\title{
EL PRINCIPIO DE UNA ESCRITURA. \\ LA HUELLA DEL SILENCIO EN LA LÍRICA METAFÍSICA DE CHONA MADERA
}

JOSÉ MANUEL MARTÍN FUMERO

CEAD de Santa Cruz de Tenerife "Mercedes Pinto"

jmarfum@gobiernodecanarias.org

RESUMEN: En este trabajo se realiza un análisis del primer libro poético de la escritora nacida en Gran Canaria Chona Madera, que lleva por título El volcado silencio, pues en él se identifican en germen los principales valores poéticos y vitales de toda su trayectoria escritural. Su personalidad literaria es, sin duda, una de las más singulares de la lírica de posguerra insular, y esa peculiar forma de entender la relación vida y literatura es la que, a nuestro juicio, comienza a vislumbrarse con acentuados y personales matices en este libro inicial.

PALABRAS CLAVE: lírica, crítica literaria, Chona Madera, literatura femenina. 


\section{THE BIRTH OF CREATIVE WRITING. The traces of silence in Chona Madera's metaphysical lyrics}

ABSTRACT: In this work an analysis is made of El volcado silencio, the first poetry book by Gran Canaria born writer Chona Madera. Indeed, the roots of her whole writing career main poetic and life values can be found in this book. Her literary personality is undoubtedly one of the most unique of the Islands' post-war lyric, and in our opinion, it is her peculiar way of understanding the relationship between life and literature what begins to be glimpsed with personal and accentuated nuances in this her first book..

KEY WORDS: Lyric, literary criticism, Chona Madera, feminist literature.

\section{Introducción}

A sunción Madera Pérez (1901-1980), conocida artísticamente como AChona Madera, nace en Las Palmas de Gran Canaria, aunque en su ruta vital anduvo por otros puertos como Madrid y Málaga. A finales de los 60 se traslada, precisamente, a esta última ciudad donde residió hasta octubre de 1979, justo un año antes de su fallecimiento. Mujer de verso «descarnado y ardiente», en palabras de Emeterio Gutiérrez Albelo (1962: $19)^{1}$, su relación con la escritura poética comenzó tardíamente ${ }^{2}$, y es esta

${ }^{1}$ Estas apreciaciones las realiza el poeta icodense Emeterio Gutiérrez Albelo desde la publicación Gánigo (Santa Cruz de Tenerife, 1953-1969) que él mismo dirigía. En esta revista Chona Madera dio a la luz casi una veintena de composiciones. Hay que decir que nuestra poeta participó activamente en muchas publicaciones, lo que evidencia, junto a la trascendencia vital que otorgaba a la poesía, el interés que suscitó su labor poética. Junto a Gánigo, colaboraciones suyas aparecieron en Mujeres de la isla, El Eco de Canarias, Diario de Las Palmas y Alisio: hojas de poesía (Las Palmas de Gran Canaria), La Tarde, El Día y Mensaje (Santa Cruz de Tenerife), Halcón (Valladolid), Poesía Hispánica, Poesía Española y Cuadernos del Ágora (Madrid), Caracola (Málaga) o Alaluz (California).

${ }^{2}$ En efecto, comienza a publicar con algo más de cuarenta años. Es por esta razón por lo que no entendemos comentarios como este de Blanca Hernández Quintana una de las razones por las que se la suele incluir, en el marco de la literatura española en general y de la literatura escrita en Canarias en particular, en el grupo de "poetas de posguerra", junto a autores coetáneos como Diego Navarro, Ignacio Quintana, Domingo Velázquez, Félix Casanova, Pino Ojeda, Agustín Millares Sall, Servando Morales, Pedro Lezcano o Cipriano Acosta Navarro. Grosso modo, entraría perfectamente en las apreciaciones que Ana María Fagundo (1988: 5) establece para caracterizar la lírica escrita por mujeres cuyo nacimiento se cifra entre 1900 y 1940 :

Lo característico de la poesía femenina del siglo XX particularmente en el periodo que aquí interesa, es que las poetisas no suelen pertenecer ni a un grupo poético, revista, colección de poesía o tertulia como parece ser lo común en la poesía masculina. Las mujeres poetas aparecen aisladas, con excepciones por supuesto, laborando en solitario y publicando sus libros en colecciones por lo general minoritarias.

En efecto, Chona Madera rehuyó su relación con referentes escriturales que, en menor o mayor medida, pudiesen supeditar su palabra poética haciendo excluir del devenir de la misma los dictados de su intuición y su sensibilidad. De todas formas, sí consideramos que la autora estableció cierto diálogo formativo -al menos en sus inicios- con autores como Alonso Quesada, Pedro Salinas y Fernando González; al igual que su compañera y amiga Pino Ojeda, con quien abandera en Canarias en la segunda mitad del siglo XX el camino de una literatura escrita por mujeres que son conscientes de su carácter diferencial, a lo largo de toda su trayectoria ausculta su sensibilidad, su mundo interior, sacando a la luz negra un paisaje de ensoñaciones y nostalgias, haciéndonos partícipes de su inquebrantable dolor humano. Será por ello por lo que todo ese magma vivencial encontrará en la forma del diario poético de su opera prima-espacio ontológico

(2003: 101): "Nace en Las Palmas de Gran Canaria en 1901 y muere en 1980. Desde muy joven comienza a escribir poesía y colabora en diversos periódicos y revistas como Mujeres en la isla, Gánigo, Mensaje, Alaluz, y Diario de Las Palmas entre otros." Tampoco entendemos la referencia a estas publicaciones como referencias tempranas en las que publica textos poéticos, pues Mensaje, que es la más longeva, comienza a publicarse en 1945 (el subrayado es nuestro). 
personal que adquiere el diálogo consigo misma y con sus circunstancias vitales- fácil acomodo. En este sentido, hemos de ver, desde un principio, su relación con la escritura y su estilo, como un permanente proceso de construcción, y tenemos que entender su lírica como el eco recurrente de una búsqueda constante. Es, justamente, este concepto el que justifica que desde El volcado silencio $\left(1944,1947^{2 a}\right)$ podamos hacer una lectura de aquellas constantes temáticas y estilísticas que vertebran toda su obra.

$\mathrm{Y}$ es, indudablemente, el carácter autobiográfico uno de los signos distintivos que se torna en eje esencial de su dilatada trayectoria ${ }^{3}$, y a él van íntimamente ligados otros valores temáticos esenciales como el tiempo y, sobre todo, el recuerdo, que se erige como una forma personal de manejar el tiempo y de sentir (y sentirse en) el propio tiempo; a estos elementos hay que agregar el amor con su amplia y rica variedad de matices (a sus familiares y, también, el amor fraternal a los otros) el que le permitirá contemplar con nostalgia y ternura los duros trances vitales que vivió ${ }^{4}$ En este sentido, el dialogismo y el amor a Dios se convertirán en dos férreos asideros para sortear la soledad, para engancharse a la vida; y es que "vitalista" es uno de los adjetivos con los que algunos críticos han tildado toda su obra lírica, como es el caso de Sebastián de la Nuez (1992: 15), para quien Chona Madera "no se revela como poeta hasta su publicación de

${ }^{3}$ Esta obra es la siguiente: El volcado silencio (1944), que aparece en la colección dirigida por Juan Manuel Trujillo que lleva por título Colección para treinta bibliófilos (Ginoeceum Canariae Minerva), Las Palmas de Gran Canaria: Imprenta Minerva, vol. I. En 1947 aparece una segunda edición en Madrid: Gráfica Signa; Mi presencia más clara (1955), editada en Madrid al cuidado de Rafael Millán, Agora; Las estancias vacías (1961), editada en la Imprenta Rexachs en Las Palmas de Gran Canaria al cuidado de Manuel González Sosa, con un prólogo de Luis Benítez Inglott; La voz que me desvela (1965), colección Tagoro n. 9, Las Palmas de Gran Canaria: Imprenta Babón:; Los contados instantes (1967, editado en libro en 1973) ediciones del Excelentísimo Cabildo Insular de Gran Canaria; Continuada señal (1970), con prólogo de Gracián Quijano, Málaga: Gráficas Garcayo; Mi otra palabra (1977), Málaga: Dardo; y, finalmente, Obras completas (1979), con prólogo de Sebastián de la Nuez, Barcelona: Ediciones Rondas. Por esta última referencia mencionaremos los poemas que tomemos para nuestro artículo, consignando junto a la cita la página entre corchetes.

${ }^{4}$ Una de sus hermanas, María Fernanda, murió muy joven. También falleció en plena juventud -apenas contaba con 38 años- el que fue su único amor, el poeta teldense Montiano Pláceres - pseudónimo de Pedro Regalado.
'El volcado silencio', dentro de la línea de los grandes poetas vitalistas de profundo sentimiento e intimismo como Garcilaso, Antero de Quental o nuestro Alonso Quesada.”

Son todas estas piezas las que, tras su lectura, nos hacen ver el primer libro poético -y toda la obra- de Chona Madera como profundamente metafísico y contemplativo: la poesía es una forma de vivir, de ser, a la vez que una manera de desahogo, una vía de escape; dialogar y comunicar son maneras de encontrar, desde la literatura, el sosiego necesario para ausentarse de la soledad, para sentirse unida a los otros y apegada a la propia vida. En este sentido, la poesía se transmuta en el inexorable nexo entre lo objetivo y lo subjetivo, la realidad y la emoción que despierta; este es el punto de partida de El volcado silencio, así como de toda una vida de intensa labor literaria.

\section{La lírica metafísica en El volcado silencio}

En palabras de Andrés Hernández Navarro (1980: 8), “Chona tuvo el raro privilegio de su sensibilidad. Analizando la vida, soñándola. Fue una autodidacta. La lectura constante y esa expresión suya valorando, estudiando el mundo en torno." Esta es una síntesis válida que sostiene los puntos cardinales de El volcado silencio, cuya primera edición, de 1944, contó con apenas 31 páginas y de la cual solo se imprimieron 50 ejemplares numerados; la segunda edición, que es la que forma parte de sus Obras completas, sale a la luz tres años más tarde y cuenta con 84 composiciones. El título de este primer poemario es ya altamente simbólico, y en él conviven íntimamente los términos "volcar" y "silencio": el verbo implica, precisamente, deshacerse de un contenido, vaciarse con cierto ímpetu, como si la propia poeta se viese como un recipiente, con lo que, tras esta acción, queda la nada, el vacío, los ecos del silencio.

En relación con todos estos valores esbozados está, como ya hemos hecho notar, el diálogo, la esencia de una poesía íntima, sencilla y directa; en palabras de María Victoria de Lara (1960: 59), su lírica "es una poesía íntima, directa, sencilla, capaz de poderosas sugerencias emotivas y claras imágenes sensoriales [...]. Es una poesía sentida y expresada sin 
los acicates del medio ambiente; por necesidad de expresión." En sus tres primeros poemarios encuentra, como unificadora singularidad, "la forma de comunicar o transmitir la emoción.” (1960: 60) En esta misma línea podemos situar las sugerencias críticas de José Quintana (1976: 12), para quien "su poesía es una consustancialidad de 'evocación-sentimientoemoción-sensibilidad-comunicación”. Otro crítico, Jordé [José Suárez Falcón] (1956: 3), estima que Chona Madera es la poetisa "de la intimidad cordial"; en su opinión:

Compone las estrofas con clara sencillez, imágenes expresivas y adecuadas metáforas huyendo siempre de tópicos poéticos gastados. [...], cuando experimenta la necesidad de exteriorizar sus sentimientos se traducen en sus páginas líricas destellos de imaginación soñadora y reflejos de su modo de sentir y ver las cosas íntimas. Estados de ánimo, paisajes interiores, panoramas sintéticos de lo que es la vida e interpretada por su espíritu.

Este mismo autor (1956: ibid.) cree que Chona Madera, al igual que Bécquer, busca la "vibración emotiva" y logra "sin salir del suelo insular [que] la fantasía viaje y recorra el universo."

Es, precisamente, la inmediatez con la que impregna el hecho percibido la que intensifica su carácter comunicativo. La emoción será el punto de convergencia entre la realidad y la visión en muchos poemas; es el modo para penetrar en el sentido trascendente de todo, sintiendo en el tiempo su valor atemporal, diríamos, casi, que su excepcionalidad. El contraste fuera-dentro, como veremos, es otro de los elementos que da, por una parte, mayor vigor poético a sus composiciones y, por otro, visibiliza el íntimo diálogo entre vida y literatura que, como hemos anunciado, toma cuerpo en el carácter autobiográfico de su palabra, como en el poema que abre el libro, titulado "Solo diez años hace":

Solo diez años hace de tu partida, hermana,

y tu vida aún conserva su más cordial cadencia;

mas vivo por entero absorta en la mañana

presente y dolorosa, que amortajó tu ausencia.

Mi corazón fraterno no cerró su ventana con lutos que quitaran sabor de confidencia

al diálogo constante de nuestra vida, hermana;

y mi presencia sigue supliendo a tu presencia.

[...] [p. 13]

Refiere esta composición el recuerdo de su hermana desaparecida, un recuerdo que también está presenta en el poema "Para los cementerios" (“iQue todos sois / la tierra de mi hermana!” [p. 25]); en otros textos trae al presente de la enunciación a su abuelo, al poeta Alonso Quesada o a la sirvienta de su casa cuando era niña. José Quintana (1976: 12) expone que este aspecto, el recuerdo de los seres queridos, del hogar, de la infancia, es un rasgo concomitante en la poesía de algunas mujeres, como la propia Chona Madera, Josefina de la Torre, Pino Ojeda, Pilar Lojendio, Violeta Alicia, Aleyda Yglesias, entre otras, que se alzan como bastiones de la poesía moderna que se aleja de viejas formas y temas:

[...] tenemos modos comunes en ellas, una de las más acusadas es la ensoñación familiar, y en asomar del hogar a los versos surge la imagen común filial, la casa desaparecida, que evoca y acerca a los seres queridos, vivos o muertos, con idéntica prestancia y vigor, cual si se tratara de las ensoñaciones y ansias de mujer en la atracción poética que saben expresar, [...].

Un rasgo clave en este primer libro será el uso del verso largo, reflexivo, con ligeras asonancias que marcan un refuerzo del contenido frente a la forma, algo que podemos relacionar directamente con lo que algunos críticos han tildado genéricamente de estilo descuidado o "informalista" redundando esto, precisamente, en el eminente carácter comunicativo de su discurso poético. El poema "Cinco de enero" es otro ejemplo en que se arrulla el recuerdo de momentos protagonizados por eternas sonrisas, momentos en que la imaginación se refugia, nuevamente, en su cuna, la infancia:

\section{$[\ldots]$}

${ }^{5}$ Así, al menos, lo han visto Joaquín Artiles e Ignacio Quintana (1978: 350), para quienes "su estilo, predominantemente informalista, nada tiene que ver con el garcilasismo".

UNED. REI, 6 (2018), pp. 89-107

ISSN 2340-9029 
-¡Han dejado unos juguetes!

se ha oído la voz del ama.

Descalzo y loco tropel...

¡Oh, mi muñeca mulata!

¡Toda en sorpresa se abre

la rosa de la mañana,

y los Reyes han colmado

los zapatitos... y el alma!

II

Hoy son otros los caminos

menos hermanos... la casa...

Solo una vez, solo una

la alegría de la infancia.

[...] [p. 20]

El contraste entre el pasado alegre y el presente atormentado robustecen el carácter ontológico de su lírica, uno de los signos distintivos que le dan autenticidad. Margarita (1965: 6) destaca que "lo importante es su diálogo trascendido de ternura universal", un diálogo que se produce entre el recuerdo de la primera parte de la composición, donde el yo poético entabla un fraternal discurso con el tiempo pasado, y la segunda parte, en la que desaparece la visión de los momentos felices de los primeros años de vida cercenada por un duro presente de ausencias. De este modo, los recuerdos se tornan en sólidos diques que contienen su vitalismo, a la vez que constituyen la principal vereda para ahondar en sí misma, para sobrellevar con serenidad el dolor por tanta pérdida.

También este dolor, precisamente, se serena gracias a la ternura con la que el yo poético responde ante el dolor de los otros. Esta respuesta fraternal es la que se encuentra en poemas como "Por mi calle", "Sonrisa buena, tuya..." o en estos versos del poema "Lo fraterno":

Mía es siempre la pena de todo el que padece;

del que sortea en derrotas las mares encrespadas;

del que trajo en herencia una triste locura,

y el que, sin culpa alguna, lleva muchas, lloradas; del que se cree solo por ignorar que soy

la dulcísima hermana que comparte su suerte;

del que sufrió en silencio la zarpa de la muerte;

y el que lloró sin tregua por su pupila ciega.

[...] [p. 30]

La fraternidad es otra forma de caminar en el mundo, de sentirse viva. La declamación esticomítica, así como el uso doblemente anafórico (por conocido y por reiterado) del relativo ahondan tanto en la sinceridad como en la rotundidad del mensaje que se quiere comunicar. Esta muestra de poesía emocional delimita con claridad esta segunda raíz temática, donde a través de la palabra cobra eterna presencia la huella vital de los otros. El dolor se vuelve tanto una forma de sentir la vida y de identificarse con los otros como una manera de percibir el cosmos en una suerte de apacible contemplación. Desde la palestra de El Museo Canario, Ángel Johan (1944) reseña, justamente, El volcado silencio desde esta perspectiva pues, según él, el silencio implica intimidad y la angustia propia y de los otros que, objetivada, adquiere la necesaria autonomía para que pueda establecerse con ella un trascendente diálogo metafísico.

Este dolor como forma intensa y sincera de amar cobra notables bríos en sus dos primeros poemarios al ligarlo al tema de la madre, al hecho de ser madre. De este modo, los recuerdos de su niñez aparecen tiznados de una tristeza más lánguida, si cabe, al rememorar a su madre y clamar que no podrá continuar su papel por no poder serlo ella misma. Esta certeza martillea su conciencia y la tiñe de oscuras tonalidades metafísicas; así en "Estas manos":

Estas manos que nunca

taparon a un hijo,

ni lavaron nunca

sus carnes rosadas,

se duelen de haber nacido

para nada.

Mi madre en mí queda

como obra truncada.

¡Qué pena por ella! 
Yo hubiera querido prolongar su savia; pero a veces digo, para mi consuelo: ¡nadie por mi culpa llorará su duelo! [p. 29]

Junto al coloquialismo de su dicción lírica, sobresale en poemas como este el epifonema final, donde el uso de la exclamación acentúa su valor sentencioso: el consuelo en que se resuelve esta composición es la respuesta serena a su constante estado de dolor. Ya Lázaro Santana (1974: 18) apuntaba que la poesía de Chona Madera es "una reelaboración de los temas cotidianos de Quesada, vistos con una nueva perspectiva y una mayor insistencia en la expresión coloquial." En efecto, en este poema todos los recursos poéticos, especialmente los encabalgamientos, orientan su decurso hacia cierta tonalidad narrativa de corte realista, lo que enfatiza en gran medida la inmediatez de su percepción como acto comunicativo. Otro elemento que no podemos dejar pasar, y que abunda en El volcado silencio, es la declamación negativa: son, precisamente, los encabalgamientos los que otorgan un alto grado de relevancia a términos de valor negativo, como "nunca", "nada" o "truncada". Este estilo llano, cercano al uso cotidiano del idioma -como el propio asunto que trata la composición- puede apreciarse también en composiciones como "Cuando cierto es amor", "Toda mi infancia pasa..." o "Quejas de amigos".

Decíamos, además, que es otro aspecto ya presente en su poesía primera -y que se acentuará en libros posteriores- el uso de versos con valor sentencioso; efectivamente Cristóbal de Castro (1944: 3) ${ }^{6}$ resalta que en este poemario encontramos "sentimientos que sugieren ideas. De ahí su brevedad de sentencias, su densidad de máximas." Este recurso está muy relacionado con el empleo de la esticomitia, y ambos elementos acrecien-

\footnotetext{
${ }^{6}$ El artículo del que tomamos la cita se publica en el rotativo madrileño $A B C$, Madrid (26 de septiembre), p. 3.En el mismo periódico vuelve a aparecer el 29 de diciembre de 1945, en la página 19 con un nuevo título, "Chona Madera, la samaritana sedienta". Esta última versión será reproducida en la revista Canarias: órgano de la asociación canaria de socorros mutuos de la República Argentina en la página 36 del número que aparece el 1 de febrero de 1947.
}

tan el valor experiencial y el carácter confesional de todo el libro, amén de intensificar la noción de que darse a los otros, desvivirse en la literatura, compartir las personales circunstancias es una buena forma de mostrar el verdadero amor: escribir es una forma de amar, la más alta cima que persigue la vida. En este orden de cosas, tenemos la plena convicción de que su verdadero mundo no era el cotidiano deambular por su casa, las calles de su ciudad, sino la poesía, a la que decidió asirse como si fuera una prolongación -y justificación- de sí misma. En palabras de Jorge Rodríguez Padrón (1983: 124), su obra "sirve para mostrar en aquellos años el camino de una poesía, apasionada, emotiva y sentimental, desde luego, pero arraigada en la cercanía de lo cotidiano, en un coloquialismo que esta poeta ha sabido manejar con notable soltura y singular eficacia." No es por ello casual que alguna composición, como la titulada "Mi verso", refleje ya desde muy pronto esa conciencia metapoética:
Yo no sé si mi verso
les gustará a las gentes.
Solo sé que en murmullos
brotaron de mi fuente.
Que su cauce virgíneo
lo labró su corriente.
¡Solo sé que refrescan
el ardor de mi frente!
[P. 36]

Y es ese amor, como ya hemos ido señalando, otro rasgo sustancial con el que gana vigor y alcance comunicativo el autobiografismo metafísico de El volcado silencio. En poemas como "Por la mano que estuvo entre las mías" [p. 23] el amor perdido, esa universal forma de proyección vital en el otro, es el "cerrado silencio", la forma más dura en que se yergue la soledad en el propio ser: "Que aquí estoy triste y sin amor ninguno, / por la mano que estuvo entre las mías...” En esta misma línea está la composición "Los labios del poeta..." [p. 30], referida a su verdadero amor -el poeta Montiano Pláceres-; su recuerdo es su refugio: "Eres mi soledad, y eres mi destino, / pues que vivo prendida en tu recuerdo, amado." Esa es su única verdad, el auténtico sentido de su existencia. Esa ausencia del ser 
amado es una de las primeras astillas que recrudecen su dolor, pero también es manantial del que se nutren sus ansias por vivir; así, igualmente, en "Pardas, innúmeras, como las arenas..." [p. 44]: "En mí se agotan la ambición y el tiempo / en esta ausencia, que al corazón devora." La composición "Abrazarlo por mis brazos" [p. 46] es, también, un desconsolado canto al amor perdido, arrebatado por la muerte: "Mi amor..., en un cementerio. / ¡Dolor!... ¿Dónde lo hay mayor / que aquel que trajo la muerte?”

"Mi sueño" [p. 22] es uno de los mejores poemas del libro, y en él el actor principal es el murmullo del silencio, que aparece personificado y, de este modo, objetiva la soledad del yo, muro que es traspasado gracias al propio acto confesional que supone convertir en literatura el desgarro íntimo:

Mi sueño -que ya no es sueño porque no es sueño de nadiepronunció un profundo "no" y se me quedó en la calle.

Mis ilusiones se fueron a desandar los caminos que emprendieron jubilosas, sin contar con el destino.

Bellas ilusiones; sueños;

¿dónde estáis?

Soledades han quedado

convertidos;

y yo, en medio de ellas,

como el muerto

entre los cirios.

El tópico ubi sunt? concreta el punto de contraste entre los momentos felices - de sueños e ilusiones- y el destino, sujeto al libre albedrío. Unos y otras son la plasmación en el alma del latido de la vida, y su ausencia amortaja la existencia. El carácter metafísico de la composición se ve reforzado tanto por la presencia de la primera persona a modo de diario de confesiones como por la tonalidad conceptista, de tenue eco quevedesco.
Por otra parte, en opinión de Pedro Perdomo Acedo (1947: 63), "en este volcarse de lo silencioso queremos ir comenzando a ver la actitud cósmica de esta nueva poetisa que con su voz tan personal viene a enriquecer la pléyade de nuestros auténticos poetas." Esa actitud cósmica se concreta, en palabras de este crítico (1947: ibid.), en "el sentimiento cósmico del amor." Hay una suerte de transfiguración constante del tema del amor a través del dolor, así como una concentración del sentido, reducto último de su medular intimismo. Para Blanca Hernández Quintana (2000: 64), "Chona Madera va encontrando su identidad en la nostalgia de un tiempo pasado que no regresará jamás. Su silencio habla y grita con rebeldía, y es desde ese silencio donde crea un espacio en el que construye su voz, su propio yo personal y concreto a través de la palabra." "Ausencia" es uno de los poemas más significativos y logrados en este sentido, a la par que uno de los que aparece con mayor frecuencia en las antologías que recogen la producción de Chona Madera ${ }^{7}$; es por ello que lo transcribimos completo:

El día que te deje, definitivamente,

tú tendrás este aire de todas las mañanas;

cuando ya me levanto para empezar el día,

cama que me cobijas, blanda, mullida cama.

Y pensar al mirarte así, desarreglada,

que tú serás quien diga más de la ausencia mía.

Porque, ¿habéis visto algo que más hable de un muerto,

que al entrar en su cuarto, ver la cama en desorden, ver la cama vacía?

Nada tendrá la fuerza que tú, en ese momento.

Ni la caja en que yazca -que será cosa nueva-.

$\mathrm{Ni}$ todo el aparato de los paños mortuorios.

Ni la luz amarilla, que difunde la cera.

\begin{abstract}
Algunas de estas antologías, a modo de muestra, son las que realiza Sebastián de la Nuez Caballero (1992): Antología de la poesía canaria del siglo XX, Londres: Forest Book, y (1993): Literatura canaria contemporánea I. Las Palmas de Gran Canaria: Edirca. A estas hay que agregar las que preparan Félix Casanova de Ayala (1989): Los mejores poemas de ayer y de hoy. Centro de la Cultura Popular Canaria: La Laguna, Lázaro Santana (1969): Poesía canaria. Antología 1939-1969. Las Palmas de Gran Canaria, colección Tagoro y, finalmente, Eugenio Padorno (2006): Coro femenino de poesía canaria. Islas Canarias, Gobierno de Canarias.
\end{abstract}

UNED. REI, 6 (2018), pp. 89-107

ISSN 2340-9029 
Por eso este beso ahora, esta larga mirada, que una ternura siento por ti, de despedida...

Por la paz, y el descanso, que eres para mis noches.

Porque no podrá ser, en el último día,

la mirada, y el beso, y este íntimo instante,

y la flor de mi verso, con la ternura mía...

[P. 37]

Como hemos venido argumentando, el dialogismo es el medio poético para hacer efectivo ese deseo de deshacerse en la palabra; ya María Rosa Alonso (1947: 418) definía este primer libro como "voz y grito", como poemario de íntimo estremecimiento, que ya denota un hondo y apasionado temperamento lírico y, como ya hemos apuntado, sin grandes lecturas poéticas preliminares y con ciertas caídas e irregularidades en el manejo de los aspectos formales. En esta estremecedora composición, el diálogo permite pasar de lo interior a lo exterior, de lo objetivo a la visión personal, en la línea ya apuntada por María Victoria de Lara. En efecto, la presencia del yo y el tú a través del dialogismo profundiza en la emoción, a lo que ayuda el empleo de insistentes recursos de recurrencia (anáforas y algunas bimembraciones) así como el uso de un estilo nominal que precisa su carácter reflexivo y metafísico, a lo que hay que añadir el final abierto, que redunda en las mismas ideas. Junto a estos elementos, volvemos a insistir en la importancia de los versos esticomíticos, que son verdaderos aldabonazos, como la propia negación que precede a formas verbales en futuro que, así, se tornan en futuros lapidarios. Recordar la belleza del pasado, de lo que fue y de los que estuvieron produce un intenso dolor pero, a la vez, otorga una nueva vida tanto a lo recordado como al sujeto que recuerda. Recordar es otra forma de mostrar amor, de que el fuego nos haga revivir, de vencer esa negación del tiempo que es la muerte, es otra manera de encontrar la luz y el sentido a la existencia. En "Lo cierto es que soy así" [p. 38] afirmará, en esta misma línea: "Llanto y más llanto por todo: / por la alegría, por la pena. / Hay algo que me encadena / al manantial del sufrir", y ese algo es el recuerdo. En otra composición, "Si ya somos..." [p. 34], la rememoración se convierte en aliento vital y lo redescubre como sentimiento, al darle vida: "deja que sueñe que ya todo ha sido, / que eres a mi resto, dulce aliento, / porque sustraje tu imagen al olvido / de la que lle- no está mi sentimiento." En poemas como los anteriores, la autobiografía íntima adquiere tonos dramáticos que toman cuerpo de forma evocadora.

La angustia existencial que todo este cúmulo de desazones genera en su alma, encuentra en Dios verdadero y sereno refugio. Al ser preguntada por la época de la Historia le hubiese gustado vivir, responde lo siguiente (1965: 6):

En la de Cristo, me hubiese gustado conocerlo. Aunque me gustan los adelantos y admiro al hombre profundamente y me parecen mentira los prodigios conseguidos por el cerebro humano, con todo mis alas van hacia Cristo, hacia su paso por la tierra. Me hubiese gustado confundirme con la muchedumbre que lo seguía...

Esta búsqueda de la profunda comunión con Dios aparece de forma habitual en muchas composiciones, como en las tituladas "La última mirada” [p. 25], donde confiesa a Dios la razón de su pena: la ausencia del ser amado ("porque solo él fue mi dueño / todo ensombrece el dolor...”); así también en "Letanía a Cristo" [p. 39], donde El Creador es "el que dio en recompensa a mi noche la calma." También en la composición “iEs eterna la vida!" la eternidad del ser encuentra escapatoria en el arte, la amistad, el amor, la emoción que despiertan las cosas bellas en las que el espíritu, como ya hiciera Dios, posa sus alas:

¿Es eterna la vida?...

En la gracia divina del arte.

En la amistad por la nobleza ungida.

En el rato de amor.

En la pura emoción por bellezas nacida.

En toda cosa,

que el espíritu sienta desplegadas sus alas,

¡i Es eterna la vida!!

[P. 23]

"En este día de invierno" [p. 28], incluso, atisbamos cierto tinte ascético, al entender que el alma, para vivir en plenitud, tiene que eliminar las pasiones. En este caso, la cercana muerte de un niño le trae el triste 
recuerdo de un espíritu joven que, como ella misma, sabe que nunca encontrará el amor verdadero, esa luz perenne del alma:

$$
[\ldots]
$$

Oh, esa pobre cadena de eslabones que nunca

te darán el secreto de un encanto que existe.

Ser siempre tan ligero me parece tan triste;

no saber de esa miel única y milagrosa

que, en unos mismos labios, sabe siempre a azahar.

[...] [P. 28]

Es posible que, por poemas y planteamientos como este, críticos como Félix Casanova de Ayala (1967: 8) relacionaran a Chona Madera con Santa Teresa de Jesús: "Chona es una poeta sobria y eficaz, con cierto corte teresiano en su más reciente obra, muy de nuestro tiempo, que sabe matizar la sequedad de su léxico con una deliciosa y femenina intimidad."

Su lírica, por momentos, es contemplativa, llena de sustantivos, de ideas. Estas leves gotas de optimismo vitalista contrastan con los abundantes claroscuros de este libro primero; en composiciones como "Vencidas mis rebeldías" [p. 25] la renunciación, que apaga las ansias de ser del alma, es la única respuesta de la poeta: le da sosiego y tranquilidad, pero lo riega todo de pesadumbre, a la vez que le hace mirar hacia sus adentros con ternura. Así se dibuja su universo, se crea su espacio de placidez contemplativa, donde dialoga con la soledad, esencia de su ser, como en el poema "Bisoña ha de ser la vida...":

$$
[\ldots]
$$

La vida, si lo es de veras, con hábil pena nos labra y el corazón nos desgarra por un motivo cualquiera.

¡Ay, que la vida es morir sin el morirse de veras!

Llévate la mía, viento,

que nada me importa ya;

llévate la mía, viento, que nadie lo va a notar.

¿No sabes, viento? Mi vida, padece de soledad.

[P. 27]

Esa soledad le hace enfrentarse a la muerte, pero sin retórica, lo que hace que muestre en versos descarnados y ebrios de sencillez un profundo sentimiento metafísico de pertenencia a la vida. En palabras de María Rosa Alonso (1962: 3),

[...] sus versos, llaga viva, trascienden tal desgarradora humanidad que anegan los valores literarios -no ciertamente escasospara atragantarnos de raíz con el mensaje estremecido.

[...] lo extraordinario de esta criatura que es la poetisa de Gran Canaria está en que vive de la muerte, pero no de su retórica, como le ocurría al poeta romántico, sino que en ella cobra autenticidad lo que se ha llamado en estos últimos tiempos "angustia existencial", que en Chona es razón de vida. Y ayuda a lograrlo justamente su escasa "literatura", la higiene de carpintería poética por ella usada, la sobriedad de la palabra, que cobra rigor poético, en tanto hondura estremecida de pura humanidad. Existencial y eterna poesía, [...].

\section{Conclusión}

En opinión, nuevamente, de María Rosa Alonso (1947: 418) "una mujer hace mejor poesía íntima que poesía descriptiva; traduce al exterior el drama recóndito de su intimidad y hace de él personaje y destino." El volcado silencio es, pues, un diario íntimo tiznado de dolor por los familiares desaparecidos, por los amigos que ya no están; en toda su obra late el pulso justo de su itinerario vital, en el que vida y literatura son proyecciones una de la otra, y la melancolía es la urdimbre que atenaza uno y otro extremo. A nuestro juicio, estos mimbres otorgan una notable singularidad a toda su obra y es uno de los ejes que vertebran su proceso compositivo. Chona Madera es mujer que se expresa como poeta de amor y dolor intensísimos, con un profundo carácter vitalista que encuentra cauce y refugio en las 
vivencias y en los recuerdos de los seres que se fueron. Cierto vacío ontológico, pues, es el signo que atraviesa toda la obra de esta poeta elegíaca, una senda que tiene en El volcado silencio su primera síntesis.

Recibido: $15 / 03 / 2018$

Aceptado: 23/05/2018

\section{Referencias bibliográficas}

Alonso, María Rosa (1947), "Notas bibliográficas. Chona Madera. Volcado silencio", Revista de Historia, La Laguna, nº 79 (julio), pp. 418-419.

---- (1962), “Cartas merideñas. A Chona Madera en Gran Canaria”, Diario de Las Palmas, Las Palmas de Gran Canaria (26 de julio), p. 3.

Artiles, Joaquín y Quintana, Ignacio (1978), Historia de la literatura canaria, Excma. Mancomunidad de Cabildos de Las Palmas de Gran Canaria, pp. 350-352.

Casanova de Ayala, Félix (1967), "Joven poesía de Las Palmas”, El Día, Santa Cruz de Tenerife (23 de noviembre), p. 8.

Castro, Cristóbal de (1944), "La samaritana sedienta", ABC, Madrid (26 de septiembre), p. 3.

Fagundo, Ana María (1988), "Poesía femenina española del siglo XX: 1900-1940”, Alaluz, California, Año XIX n. 1-2 y Año XX 1-2 (primaveraotoño 1987 y 1988), pp. 5-24.

Gutiérrez Albelo, Emeterio (1962), “Las estancias vacías”, Gánigo, n. 40, Santa Cruz de Tenerife (enero), p. 19.

Hernández Navarro, Andrés (1980), “Tiempo para vivir, tiempo para morir", en El Eco de Canarias, Las Palmas de Gran Canaria (30 de octubre), p. 8.

Hernández Quintana, Blanca (2000), "Mujer y Literatura en Canarias”, La Plazuela de las Letras, Las Palmas de Gran Canaria (junio), pp. 62-66.
---- (2003), Escritoras canarias del siglo XX, Ediciones del Cabildo de Gran Canaria: Las Palmas de Gran Canaria, pp. 101-111.

Johan, Ángel (1944), “El volcado silencio de Chona Madera”, El Museo Canario, Las Palmas de Gran Canaria, nº. 9, pp. 84-88.

Jordé [José Suárez Falcón] (1956), "Poesía del parnaso insular”, Diario de Las Palmas, Las Palmas de Gran Canaria (11 de abril), p. 3.

Lara, Ma. Victoria de (1959), "El modo poético de Chona Madera”, Revista de Literatura, Madrid (enero-junio) Tomo XV, $\mathrm{n}^{\text {os }} .29-30$, pp. 59-71.

Madera, Chona (1979), Obras completas, prólogo de Sebastián de la Nuez, Barcelona: Ediciones Rondas.

Margarita [Brito Sánchez] (1965), “Chona Madera”, en El Eco de Canarias, Las Palmas de Gran Canaria (6 de mayo), p. 6.

Nuez Caballero, Sebastián de la (1992), "La poesía contemporánea en Canarias: dos generaciones de la posguerra (1940-1960)", Zurgai, Bilbao (junio) pp. 10-20.

Perdomo Acedo, Pedro (1947), "Poesía y volcado silencio", El Museo Canario, $\mathrm{n}^{\text {os }}$. 21-22, Las Palmas de Gran Canaria (enero-marzo), pp. 51-68.

Quintana, José (1976), “Renovación del 'modo poético’ de Chona Madera”, en El Eco de Canarias, Las Palmas de Gran Canaria (23 de mayo), p. 12.

Rodríguez Padrón, Jorge (1983), “Ochenta años de literatura (1900-1980)" en Canarias siglo XX, Las Palmas de Gran Canaria: Edirca, pp. 101-152.

Santana, Lázaro (1973), “Los Contados Instantes”, Canarias 80: semanario regional, Las Palmas de Gran Canaria (6 de octubre), p. 58.

----- (1974), “30 de Arte y Literatura”, Aguayro, Las Palmas de Gran Canaria $\mathrm{n}^{\circ} .50$ (abril), pp. 17-20. 